\title{
Pleural tumor simulating localized pleural fluid
}

\author{
Hiroko WATANABE ${ }^{1}$ \\ Tomohiro TAMURA ${ }^{1}$ \\ Hiroaki SATOH $^{1}$
}

\author{
${ }^{1}$ Division of Respiratory Medicine, Mito Medical Center, Tsukuba University, \\ Mito, Japan \\ ${ }^{1}$ Tsukuba Üniversitesi Mito Tıp Merkezi, Solunum Bölümü, Mito, Japonya
}

An 85-year-old woman was referred to our hospital with a 2-week history of heart failure and respiratory tract infection presented with fever, cough and sputum. Chest radiograph revealed bilateral pleural fluid and cardiomegaly, and a well-defined, smooth surface mass suggesting localized intralober pleural fluid (Figure 1). Laboratory tests revealed an increased white blood cell count of $15.000 / \mathrm{mL}$ and an elevated serum level of C-reactive protein of $8.5 \mathrm{mg} / \mathrm{dL}$. She refused admission and received garenoxacin (400 mg/day) for 10 days. Chest radiograph after the therapy showed improvement of bilateral pleural fluid and cardiomegaly (Figure 2). Chest CT scan 3 month after the therapy revealed a chest wall mass with destruction of the ribs, which was confirmed as undifferentiated lung cancer pathologically (Figure 3).

In our patient, a presumptive diagnosis of localized pleural fluid was made based on the patient's clinical history and laboratory and radiologic findings. Antibiotic treatment was successful to control the respiratory tract infection and its related cardiac failure and, subsequently, follow up with chest radiograph was performed to confirm the shrinkage of suspected localized pleural fluid. To differentiate pleural tumorfrom localized pleural fluid, it is important to examine the shape of a tumor with soft tissue attenuation, particularly with respect to irregularity of the pleural thickness and the existence of projections in the cavity (1). Another helpful CT finding for differential diagnosis is bony destruction $(1,2)$. Bony destruction caused by pleural tumor is not rare and usually shows a permeative pattern of destruction, whereas bony destruction caused by osteomyelitis in empyema is rare and usually shows osteolytic and expansile pattern destruction $(1,2)$. CT findings, in addition, helpful for differential diagnosis between pleural tumor and localized pleural fluid, include abnormal mass of soft tissue attenuation, irregular thickness of the pleura and the presence of permeative bony destruction.

\section{Yazışma Adresi (Address for Correspondence)}

Dr. Hiroaki SATOH

Division of Respiratory Medicine,

Mito Medical Center, Tsukuba University, MITO - JAPAN

e-mail: hirosato@md.tsukuba.ac.jp 


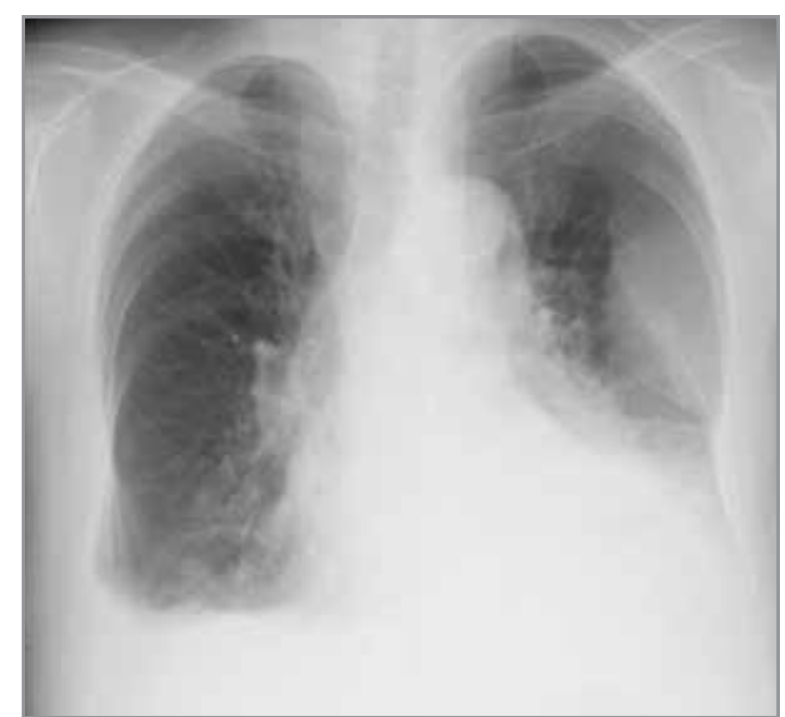

Figure 1. Chest radiograph revealed bilateral pleural fluid and cardiomegaly, and a well-defined, smooth surface mass suggesting localized intralober pleural fluid.

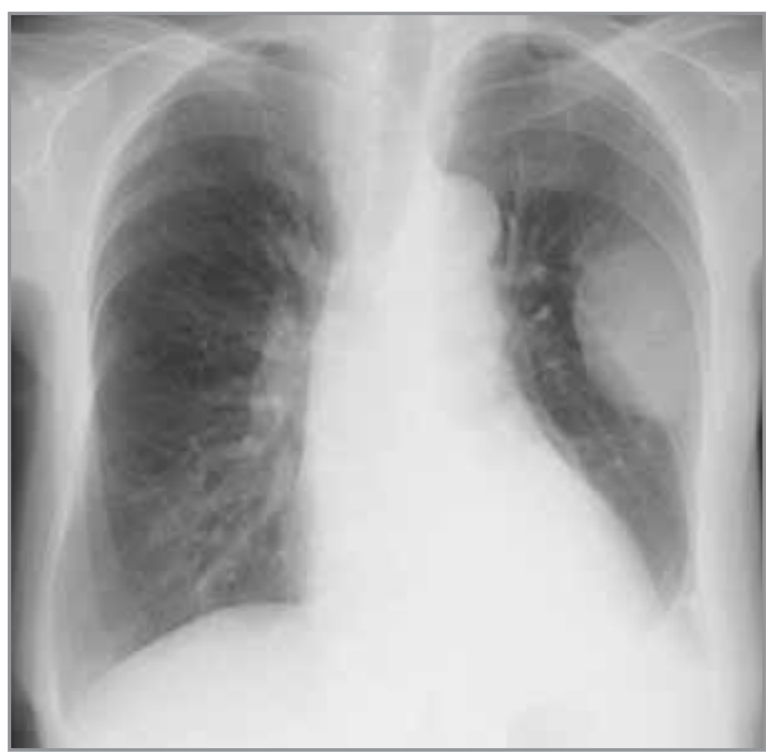

Figure 2. Chest radiograph 2 months after the therapy still remained a huge mass.

Malignant pleural tumor is not a rare condition and is sometimes likely to occur at the same time of other disease such as pneumonia and cardiac failure with cardiomegaly and bilateral pleural fluid (3). Physicians should rule out the possibility of pleural tumor in patient with cardiac failure with pleural fluid, especially those with suggestive localized pleural fluid. Careful radiologic assessment with $\mathrm{CT}$ and aggressive biopsy procedures are necessary.

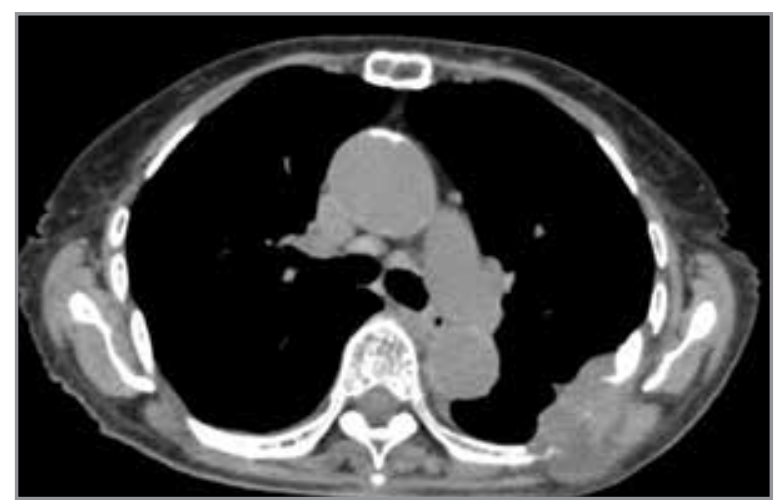

Figure 3. Chest CT scan 3 month after the therapy revealed a chest wall mass with destruction of the ribs.

\section{REFERENCES}

1. Bonomo L, Feragalli B, Sacco $R$, Merlino B, Storto ML. Malignant pleural disease. Eur J Radiol 2000;34:98-118.

2. Edelstein G, Levitt RG, Slaker DP, Murphy WA. CT observation of rib abnormalities: spectrum of findings. I Comput Assist Tomogr 1985;9:65-72.

3. Hasse J, Wertzel H, Kassa M, Burgard G. Thoracic cancer surgery in the elderly. Eur I Surg Oncol 1998;24:403-6. 